\title{
CONTEXTOS E PROCESSOS DE MUDANÇA DOS PROFESSORES: UMA PROPOSTA DE MODELO
}

\author{
Ana Margarida Veiga Simão* \\ Ana Paula Caetano* \\ MARIA AsSUNÇÃo Flores ${ }^{* * *}$
}

\begin{abstract}
RESUMO: Neste artigo apresenta-se uma proposta de um modelo para a compreensão e análise da mudança do professor com base em resultados de três estudos empíricos realizados em Portugal. Partindo da perspectiva da complexidade, a mudança é encarada como um processo que implica simultaneamente factores contextuais, que podem ou não ser sustentados por estruturas formativas, e factores pessoais associados à aprendizagem e ao desenvolvimento profissional no local de trabalho.

Palavras-chave: Mudança do professor. Formação de professores. Cultura escolar. Aprendizagem. Desenvolvimento profissional.
\end{abstract}

\section{CONTEXTS AND PROCESSES OF THE TEACHER'S CHANGE: \\ A CONCEPTUAL MODEL}

ABSTRACT: This article draws a proposal of a model for the understanding and analysis of the teachers' change based on results of the empirical studies carried out in Portugal. Considering the perspective of complexity, the change is viewed as a process that implies simultaneously contextual factors, which may or not be sustained by edu-

* Faculdade de Psicologia e de Ciências da Educação da Universidade de Lisboa. E-mail: ana.simao@fpce.ul.pt

** Faculdade de Psicologia e de Ciências da Educação da Universidade de Lisboa. E-mail: ulfpapv@fpce.ul.pt

*** Instituto de Educação e Psicologia da Universidade do Minho, campus de Gualtar. E-mail: aflores@iep.uminho.pt

Educ. Soc., Campinas, vol. 26, n. 90, p. 173-188, Jan./Abr. 2005

Disponível em <http://www.cedes.unicamp.br> 
cational structures, and personal factors associated with learning and professional development in the work place.

Key words: Teacher change. Teacher education. School culture. Learning. Professional development.

\section{Introdução}

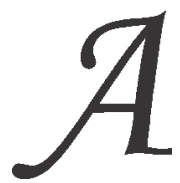

mudança tornou-se num dos temas recorrentes um pouco por todo o mundo, quer em um nível mais estrutural, quer no âmbito de intervenções mais pontuais e localizadas. Os professores encontram-se, assim, implicados em processos de mudança determinados num contexto macro e/ou num contexto micro. A(s) forma(s) como os professores lidam com a mudança depende(m) de uma variedade de factores, que decorrem de processos impostos ou mandatados ou de natureza espontânea e individual. Richardson \& Placier (2001) identificam duas perspectivas de mudança: i) a mudança cognitiva, afectiva ou comportamental de um indivíduo ou de um pequeno grupo e ii) a visão organizacional da mudança que articula aspectos estruturais, culturais e políticos da organização escolar com mudanças nos professores e no ensino.

A literatura sobre esta temática tem enfatizado a interacção entre os conceitos de mudança e de aprendizagem e desenvolvimento profissional (Marcelo, 1994, 1999; Day, 1999). Fullan (1991), por exemplo, argumenta que a mudança representa um processo recíproco entre comportamento e crenças, enquanto Hopkins et al. (1994) destacam os processos de mudança dos indivíduos ao nível do seu pensamento e da sua acção.

A mudança constitui um processo (Guskey, 1986) que envolve uma melhoria qualitativa (Watzlawick et al., 1975; Watzlawick, 1978), descontinuidades e aprendizagem double loop (Argyris \& Schön, 1974), bem como transformaçôes espaciais e temporais, que correspondem a novos entendimentos e novos modos de perspectivar o próprio processo de mudança. Se a mudança constitui um processo, ela é, ao mesmo tempo, um produto, o resultado de um processo de aprendizagem, incluindo, portanto, novas formas de pensar e de entender a prática. Por outras palavras, a mudança encerra uma dimensão interna e uma dimensão externa (Silva, 1993, 1996; Askew 
\& Carnell, 1998), implicando um processo lento que requer tempo, sendo, por isso, às vezes, difícil de identificar.

Uma análise da literatura sobre a mudança revela ainda um conjunto de ideias que nos parecem de realçar e que constituem os aspectos centrais em que assenta este artigo: i) a mudança é um processo complexo que pressupõe a interacção entre factores pessoais e contextuais; ii) a mudança é um processo interactivo e multidimensional que inclui mudanças ao nível das crenças e das práticas e a articulação entre ambas; iii) a mudança está intrinsecamente ligada à aprendizagem e ao desenvolvimento.

Neste artigo baseamo-nos naquilo que Richardson \& Placier (2001) denominam mudança voluntária ou naturalista, enfatizando o seu carácter eminentemente individual, mas integrando-a num sistema complexo de processos de mudança que se relacionam entre si. Inscrevemo-nos, assim, numa perspectiva complexa de mudança, realçando, com particular ênfase, aspectos associados à multidimensionalidade, às interacções não-lineares, à sensibilidade aos contextos e à auto-organização (Morin, 1999, 1996, 1995, 1982).

\section{Metodologia: três estudos empíricos}

Os objectivos que norteiam este artigo assentam numa metodologia que reconhece a complexidade e dinâmica do processo de mudança, bem como os contextos nos quais ela ocorre. Neste artigo pretendemos compreender a mudança dos professores com base em três estudos empíricos que incidiram sobre esta temática no quadro de um projecto de intervenção/formação e com base na mudança individual, naturalista e voluntária dos docentes. Por outras palavras, procuramos sistematizar os resultados obtidos, articulando-os com a literatura existente.

Os projectos de investigação, cujos principais resultados descrevemos neste artigo, foram realizados em 2000, 2001 e 2002. O primeiro (Veiga Simão, 2000) incluiu um projecto de intervenção/ formação para professores no âmbito de estratégias de aprendizagem com vista ao desenvolvimento de práticas reflexivas. Tratou-se de um estudo de um ano durante o qual quatro professores do ensino básico se envolveram num projecto de investigação/acção que teve como 
Contextos e processos de mudança dos professores: uma proposta de modelo

principal finalidade estimular os docentes para a descoberta das possibilidades da acção e, ao mesmo tempo, para a análise dos seus esquemas de pensamento que a podem condicionar ou potencializar. Os dados foram recolhidos com base em procedimentos quer quantitativos (escalas, indicadores estatísticos, questionários, provas etc.), quer qualitativos (entrevistas, questionários de resposta aberta, observação, estimulação da recordação etc.)

O segundo projecto (Caetano, 2001) incluiu quatro estudos de caso, cada um dos quais relacionado com situaçōes formativas distintas, em que os professores desenvolveram projectos de investigaçãoacção (um dos quais com a duração de quatro anos, outro com a duração de três anos e dois casos com a duração de um ano). No total participaram nessa investigação 11 professores dos ensinos básico e secundário. Os dados foram recolhidos no início e durante o período de formação e em follow-ups até dois anos após o seu término. Privilegiou-se a análise dos diários de investigação-formação (relativos às sessões de formação), dos diários de investigação-acção (relativos aos projectos dos professores), dos relatórios finais (produzidos pelos professores no final do processo formativo), das entrevistas iniciais e das entrevistas de follow-up (de grupo e individuais).

O terceiro projecto de investigação (Flores, 2002) teve a duração de dois anos e centrou-se na análise dos processos de mudança (voluntária ou naturalista) de um conjunto de 14 professores em início de carreira, em diferentes contextos de trabalho. Os professores envolvidos neste estudo longitudinal leccionavam nos ensinos básico e secundário. Os dados foram recolhidos no início e no final de cada ano lectivo (1999/2000, 2000/2001), tendo sido utilizadas como técnicas de recolha entrevistas semi-estruturadas, relatos e reflexôes escritas. No decorrer da investigação decidiu-se incluir outros actores, nomeadamente os alunos, outros professores que trabalhavam nos mesmos contextos escolares $(\mathrm{n}=627)$ e os presidentes dos conselhos executivos das respectivas escolas $(=18)$, no sentido de aprofundar questões ligadas à aprendizagem no local de trabalho (sobretudo no que diz respeito aos efeitos da(s) cultura(s) e da(s) lideranças(s) escolar(es) no processo de desenvolvimento profissional dos docentes) e à mudança dos professores na perspectiva dos seus alunos $(\mathrm{n}=891)$. 
Principais resultados

Em seguida, apresentam-se os principais resultados obtidos em cada um dos estudos atrás descritos. Quanto ao primeiro projecto (Veiga Simão, 2000, 2002a, 2002b, 2002c, 2002d), a participação dos professores na intervenção levou-os a tomarem consciência do seu papel de agentes de mudança e a equacionarem a pertinência dessas mudanças ao reflectirem sobre elas, avaliando-as e propondo novas transformações. Salientam-se como principais resultados, os seguintes:

- Os professores percepcionaram mudanças na sua prática lectiva em três dimensões: no nível processual, no nível das atitudes e das crenças e no nível conceptual.

- No que se refere aos aspectos processuais, foram referenciadas sete áreas: a) na sequência das actividades de ensinoaprendizagem, nomeadamente na preocupação de equacionar conteúdos conceptuais, processuais e atitudinais; b) na forma de organização social da aula, fomentando um clima facilitador da aprendizagem; c) no papel do professor e do aluno, ajudando este a caminhar para a autonomia, de uma forma responsável; d) na utilização do espaço e do tempo, tomando consciência da pressão que estes exercem sobre as possibilidades de actuação; e) na maneira de organizar os conteúdos, equacionando a necessidade de uma lógica globalizadora; f) na concepção e na utilização dos materiais curriculares, construindo-os de forma que possibilitem a reflexão dos alunos sobre os seus próprios processos de aprendizagem; g) no sentido e no papel da avaliação, ao assumir a necessidade de avaliar de forma diversificada, relativamente aos objectos e aos indivíduos, com o objectivo de tomar decisões de natureza diferente, o que leva a uma atitude de observação, averiguação e questionamento.

- As áreas de mudança referenciadas estão directamente relacionadas com mudanças no nível das atitudes (papel mais activo na ajuda à aprendizagem do aluno, visão crítica e reflexiva do processo, um questionamento sistemático...) e com o nível conceptual (a importância da reflexão sobre a prática, com referentes teóricos; a pertinência de colocar o 
professor em situação de "aprendente"; de conceder às estratégias de aprendizagem o estatuto de conteúdo...).

- Os docentes modificaram as suas crenças sobre a irrelevância da teoria e também sobre a eficácia da prática por si, na qualidade de processo formativo. $\mathrm{O}$ contacto com os problemas reais, enfrentando-os como profissionais, levou-os a reproduzir somente a cultura da instituição onde estavam inseridos, não lhes tendo provocado um suficiente conhecimento reflexivo. Ao tomarem consciência deste facto, reconheceram que a prática por si mesma não é suficiente pois, muitas vezes, as rotinas da instituição "vencem" sobre as possibilidades da reflexão crítica. Destas constatações surgiu uma nova visão da teoria, não estática mas dinâmica, como ferramenta de descoberta da realidade e como ferramenta de alternativa para poderem implementar projectos de intervenção nessa prática.

- Constatámos que só depois de algum tempo, principalmente após se terem colocado na situação de "aprendentes", é que os docentes verificaram a necessidade de formação em estratégias de aprendizagem. Para ensinar os alunos a empregarem estrategicamente os seus recursos, é necessário que previamente o professor seja capaz de aprender e ensinar, também estrategicamente, os conteúdos curriculares. Por esta razão aplicámos os princípios subjacentes à concepção das estratégias de aprendizagem (consciência, intencionalidade, auto-regulação) ao processo formativo dos professores.

- Ficou clara a necessidade de os docentes reservarem espaços na sua própria organização escolar para reflectirem sobre o sentido das práticas e equacionarem-se alternativas.

Por fim, em termos gerais, parece relevante que o processo formativo se comprometa com a prática e reflicta sobre ela, equacionando mudanças, concretizando-as e confrontando-as quer com a teoria, quer com a prática, pois essa é a via que permite a integração de estratégias diferenciadas ao mesmo tempo possibilitando que as mudanças se mantenham e generalizem, porque são compreendidas e ensaiadas. 
Qualquer que seja a estratégia formativa seleccionada, ela terá forçosamente que levar os docentes: a) a apoderarem-se da teoria das diversas disciplinas para possuírem ferramentas que lhes sirvam para a análise da realidade pedagógica que estão a viver; b) a experimentarem novas alternativas, envolvendo-se nelas (por exemplo, investigaçãoacção...); c) terem hipóteses de supervisão por parte de investigadores/ formadores que os apoiem na tarefa de analisar e compreender a complexidade das situações, colaborando na elaboração de intervenções alternativas.

Relativamente ao segundo projecto (Caetano, 2001, 2002a, 2002b), para os 11 professores envolvidos em dispositivos de formação pela investigação-acção, salientam-se como principais resultados, que associam as mudanças e os processos de formação, os seguintes:

- As mudanças mais profundas e complexas, correspondentes à contextualização e conceptualização do conhecimento e à integração de mudanças no nível do conhecimento, dos valores e da acção, surgem frequentemente associadas a situações de formação em que ocorreram processos complexos de investigação-acção, pelos quais se estabeleceram tensões e diálogos e relações de construção mútua entre diversas modalidades de investigação, entre a investigação e a acção e modalidades de acção em que a lógica de investigação, orientando para objectivos instrumentais de construção de conhecimento, está presente.

- Uma associação do desfasamento entre tempos de acção e tempos de investigação, com o desenvolvimento do distanciamento emocional, da reflexividade, do autoconhecimento e do comprometimento com a mudança.

- Uma tendência para que a estruturação e a flexibilização dos projectos e das interacções se associem ao desenvolvimento dessas qualidades no nível do pensamento e da acção, associadas, na maioria, a casos em que estes dois movimentos se interpenetram e influenciam mutuamente.

- Uma associação entre a diferenciação pedagógica dos projectos e das problemáticas, de campos de intervenção e/ ou de processos metodológicos (nomeadamente os processos 
mais complexos de diferenciação), com o alargamento de perspectivas, a contextualização do pensamento e a mudança da acção, associadas ao desenvolvimento de dimensôes éticas e de concepções pedagógicas reflexivas (em que o ensino-aprendizagem se orienta pela investigação e por princípios participativos).

- Os casos em que as relaçôes entre a escola e a formação foram mais directas e extensas, os quais incluem professores mais experientes e em que o tempo de formação foi mais longo, são, na maioria, casos em que as mudanças foram simultaneamente mais alargadas e profundas.

- As dimensões éticas desenvolveram-se pela acção, colaboração e reflexão, nomeadamente pela experiência, em situação formativa, de processos de investigação-acção e de diferenciação, confluindo, em muitos casos, para o comprometimento com valores de cooperação, participação e autonomia.

- O tempo de duração da formação e o tempo de vida dos professores parecem estar associados a diferentes resultados em termos das mudanças por estes identificadas. As diferenças apontam para maior abertura a contextos mais alargados e a maior diversificação e expansão de interesses, nos professores mais experientes, ao passo que as mudanças mais complexas, nos professores mais jovens, surgem mais frequentemente quando o foco de atenção se circunscreveu à sala de aula.

Por fim, em termos gerais, parece necessário, para que a mudança ocorra e permaneça, que haja um tempo de integração, para que se estabeleça uma relação entre mudança e continuidade (pela qual muitas dimensões se mantêm) e para que se estabeleça e desenvolva um diálogo entre os sentidos internos (finalidades, valores, atitudes, motivações individuais dos professores) e os sentidos dos seus contextos sociais.

Quanto ao terceiro projecto (Flores, 2002), de uma forma geral, foi possível identificar um conjunto de tendências de mudança junto dos 14 professores envolvidos no estudo:

- Uma perspectiva mais indutiva e centrada no aluno deu lugar a um posicionamento mais tradicional e centrado no 
professor, sendo possível identificar um padrão mais ou menos regular na forma de organizar o acto didáctico: explicação/exposição das matérias, trabalho individual de aplicação por parte dos alunos e avaliação das tarefas realizadas. Flexibilidade, individualização e atenção a interesses e necessidades dos alunos, enunciadas como características-chave de um bom ensino, foram, assim, relegadas para plano secundário, o que foi corroborado pelo aumento de trabalho escrito, de trabalhos de casa e do uso do manual.

- A emergência de uma perspectiva mais centrada no professor surgiu ligada a problemas na gestão da turma e no controlo disciplinar dos alunos, o que foi acompanhado por uma crescente ênfase na exposição dos tópicos e na diminuição da participação dos alunos nas actividades da sala de aula.

- A par de uma perspectiva mais centrada no professor, houve uma crescente ênfase no produto, como resultado do processo de socialização dos neófitos no local de trabalho. A maioria dos professores admitiu que adoptara atitudes de conservadorismo e de ajuste interiorizado (Lacey, 1977), mantendo um relacionamento cada vez mais distante com os seus colegas e com os órgãos de gestão da escola. A dimensão burocrática do ensino, a prestação pública de contas e o escrutínio público constituíram ainda questôes recorrentes nos relatos dos professores, que estes associaram a uma cada vez maior ênfase numa perspectiva de ensino centrada nos resultados.

De salientar, no entanto, que 4 dos 14 professores envolvidos no estudo seguiram uma tendência oposta, na medida em que adoptaram posicionamentos mais inovadores e diversificados na forma de perspectivar o ensino/aprendizagem, o que se traduziu por uma mudança qualitativamente positiva ao longo do tempo, manifestada pela variedade de métodos e técnicas centrados no aluno e pela criação de um clima propício à aprendizagem dos alunos (que estes também corroboraram nos seus relatos). Factores de natureza contextual (nomeadamente clima de apoio/ajuda na escola, conhecimento do contexto e dos alunos e motivação dos alunos) e de nature- 
za idiossincrática (por exemplo, visão do que significa ser professor, motivação pessoal para a aprendizagem ao longo da vida, experiências positivas como aluno(a) e aluno(a) futuro professor(a)) convergem para explicar diferenças nas trajectórias de mudança desses professores (Flores, 2003).

\section{Para um modelo de mudança dos professores}

Com base na metodologia de análise dos três estudos apresentados é possível conceber um modelo comum (ver Figura 1) relativo às mudanças dos professores.

Entre os processos de mudança identificados (acção, colaboração, investigação, teoria e reflexão) estabelecem-se interacções tensionais múltiplas (como, por exemplo, entre desafio e suporte, entre autonomia e interdependência, entre a estruturação e a flexibilidade, entre a investigação e a acção), pelas quais esses processos se influenciam mutuamente (de um modo mais ou menos acentuado), pelo que a roda representativa dessas interacções deve ser considerada uma roda móvel que põe em movimento, de forma complexa, inter-relações múltiplas.

Esses processos não podem deixar de ser considerados por referência a factores de ordem pessoal (relativos aos professores, mas também aos seus interlocutores, nomeadamente os alunos) e a factores de ordem contextual (em que o sistema educativo, a escola e a comunidade constituem os núcleos de influência mais representativos). Daí a inclusão do círculo relativo aos processos de mudança num círculo mais amplo, que representa esses factores de mudança.

Por fim, a Figura 1 representa, por meio de rectângulos inclusos, as mudanças, quer dos professores - primeiro nível de mudanças -, quer do sistema educativo, da escola, da comunidade onde a escola se insere e dos alunos. A integração destes diversos níveis decorre de uma concepção de interdependência pela qual as mudanças num nível têm repercussões em mudanças nos outros níveis. Num estudo sobre a mudança não se deve descurar dessas inter-relações, sendo importante analisar concertações e desfasamentos operados entre estes diferentes níveis.

$\mathrm{Na}$ medida em que o modelo se centra sobre as mudanças dos professores, são exploradas com mais detalhe diversas dimensôes relativas a essas mudanças. Assim, distingue-se entre um patamar que 
considera os elementos em mudança (conteúdos, áreas e tipos de mudança) e um outro patamar no qual esses elementos são considerados em formas que organizam as suas inter-relações (teorias da prática e padrões de acção). A legenda da figura especifica as dimensóes em que se diferenciam estas categorias.

\section{Figura 1}

(Concertação/desfasamento entre níveis de mudança)

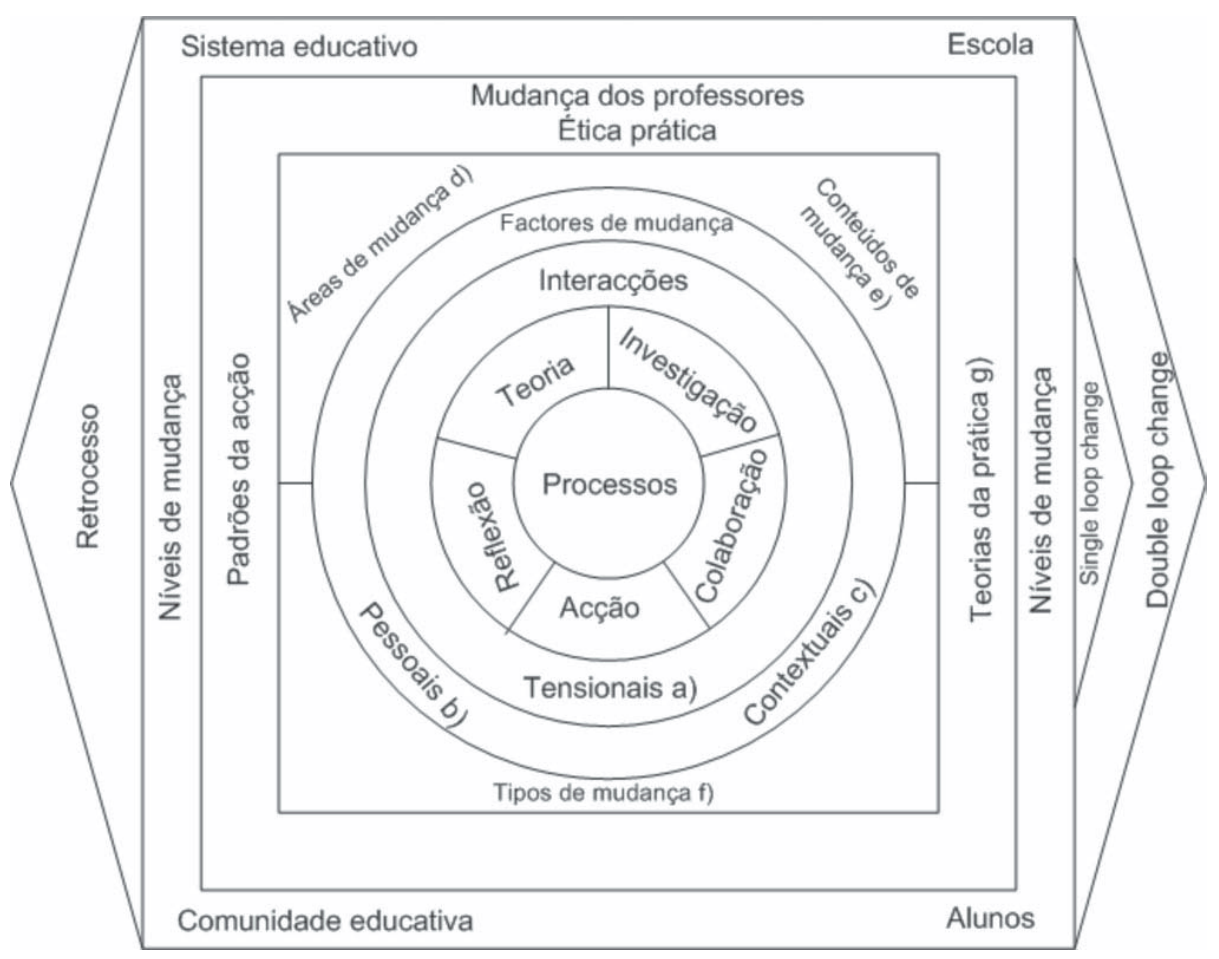

A figura pode ser interpretada a partir do centro ou da periferia, não havendo uma ordem linear de inter-relações entre as dimensões que aí se integram. No centro surgem dimensões relativas aos processos de mudança, que se repetem, em certa medida, na periferia, onde se dispõem as dimensões em mudança. As setas (representadas por meio dos triângulos da esquerda e da direita da figura) tanto apontam para mudanças com um sentido de progresso, dirigidas para a direita da figura, como para as mudanças com um sentido de regressão, apontadas para o lado esquerdo da figura. A seta dupla reforça a ideia de mudança de double loop, pela qual se forma uma dupla hélice transformadora, que aponta para níveis de mudança mais profundos: 
Contextos e processos de mudança dos professores: uma proposta de modelo

a) exemplos de interacções tensionais: entre autonomia e interdependência, entre individual e colectivo, entre a teoria e a acção, entre desafio e suporte, entre a investigação e a acção...;

b) factores pessoais: aprendizagem, motivação (expectativas, sentido de auto-eficácia etc.), história de vida;

c) factores contextuais: cultura, clima (liderança, redes de comunicação, dinâmicas de colaboração etc.), estrutura;

d) áreas de mudança: atitudes e valores, acção, saberes, competências (cognitivas, metacognitivas e motivacionais);

e) conteúdos das mudanças: conteúdos pessoais, pedagógicos (gerais e de didáctica), relativos às matérias, aos contextos particulares (alunos, classe, escola, comunidade), aos contextos gerais e a dimensóes investigativas;

f) tipos de mudança: as mudanças podem ser analisadas quanto à sua efemeridade (duradouras ou não), sistematicidade (sistemáticas ou pontuais), extensão (mudanças alargadas ou circunscritas), radicalidade (mudanças mais ou menos substitutivas) e molaridade (aglomeradas ou não);

g) as teorias da prática deverão ser analisadas quanto ao seu grau de contextualização, conceptualização, consistência interna, coerência com a acção, integração, flexibilidade, consciência metacognitiva, holismo.

\section{Conclusão}

Tendo em conta o modelo atrás apresentado, é possível extrair algumas consideraçôes, em jeito de síntese, que atravessam o conjunto dos estudos descritos:

- a mudança dos professores tende a ser positiva, alargada e aprofundada quando concorrem, de uma forma consistente, factores facilitadores no nível dos contextos gerais e específicos e no nível pessoal;

- é relevante, para a ocorrência de mudanças em profundidade, a instituição de dispositivos de suporte que permitam 
uma formação continuada, que sustentem e aprofundem mudanças em múltiplos níveis, nomeadamente as mudanças dos professores decorrentes de uma formação inicial;

- é também relevante para a promoção de mudanças duradouras, sistemáticas, alargadas e organizadas de forma coerente, em torno de teorias da prática e padrões de mudança, uma formação que desenvolva no professor o comprometimento com uma prática reflexiva, uma atitude investigativa permanente e um sentido de autoria dos projectos em que se envolve (pela utilização isomórfica, na formação, da teoria, da reflexão e da investigação em torno de projectos dos próprios professores);

- enfatiza-se uma perspectiva do professor como agente de mudança, associada ao desenvolvimento do sentido pessoal de auto-eficácia, automotivação, auto-regulação e a uma abertura e flexibilidade em face dos contextos;

- é de igual modo importante o desenvolvimento de uma cultura de escola colaborativa e de uma liderança alargada, em que a convergência, a diferenciação, a aceitação mútua e o desafio e confronto de perspectivas sejam facilitadores do desenvolvimento de padrões inovadores no nível das práticas, do desenvolvimento de teorias da prática contextualizadas, cada vez mais consistentes e coerentes com a acção, envolvendo um alargamento de perspectivas e de focos de atenção e o aprofundamento das dimensões éticas, num contexto democrático.

Por fim, importa dar continuidade a esta investigação, alargando-a a novas situações e desenvolvendo projectos conjuntos que afinem os modelos de análise e permitam uma mais ampla comparação de resultados. Preconiza-se, numa perspectiva da complexidade, que o estudo da mudança considere em simultâneo factores contextuais, tais como as imposiçôes curriculares do sistema educativo, mas também os processos de mudança suportados por dispositivos de formação e, ainda, processos de mudança espontâneos que operam por meio de formas de socialização e de processos individuais de aprendizagem e de desenvolvimento.

Recebido em junho de 2004 e aprovado em dezembro de 2004. 
Referências bibliográficas

ARGYRIS, C.; SCHÖN, D. Theory in practice. San Francisco: JosseyBass, 1974.

ASKEW, S.; CARNELL, E. (Ed). Transforming learning: individual and global change. London: Cassell, 1998.

CAETANO, A.P. A mudança dos professores em situações de formação, pela investigação-acção. 2001. Tese (Doutorado) - Faculdade de Psicologia e de Ciências da Educação, Universidade de Lisboa, Lisboa. (não publicada)

CAETANO, A.P. Complexity in teacher's change and action research. Teacher education and the achievement agenda: problems and promises in policy and practice; ICET 2002 International Yearbook on Teacher Education. Wheeling: Teacher Education and The Achievement Agenda, 2002a.

CAETANO, A.P. Teacher's change and action research. European Conference on Educational Research Online, 2002b. Disponível em: $<$ http://www.leeds.ac.uk/educol/documents.htm>

DAY, C. Developing teachers: the challenges of lifelong learning. London: Falmer, 1999.

FLORES, M.A. Learning, development and change in the early years: a two-year empirical study. 2002. Tese (Doutorado) - University of Nottingham, Nottingham, UK.

FLORES, M.A. Mapping teacher change: a two-year empirical study. Comunicação apresentada no 84. Annual Meeting of the American Educational Research Association, Chicago, 21-25 abr. 2003.

FULLAN, M. The new meaning of educational change. New York: Teachers College, 1991.

GUSKEY, T.R. Staff development and teacher change. Educational Leadership, v. 42, n. 7, p. 57-60, 1985.

GUSKEY, T.R. Staff development and the process of change. Educational Researcher, v. 15, n. 5, p. 5-12, 1986. 
HOPKINS, D.; AINSCOW, M.; WEST, M. School improvement in an era of change. London: Cassell, 1994.

LACEY, C. The socialization of teachers. London: Methuen, 1977.

MARCELO, C. Formación del profesorado para el cambio educativo. Barcelona: PPU, 1994.

MARCELO, C. Formação de professores: para uma mudança educativa. Porto: Porto, 1999.

MORIN, E. Ciência com consciência. Mem Martins: Europa-América, 1982.

MORIN, E. Introdução ao pensamento complexo. Lisboa: Instituto Piaget, 1995.

MORIN, E. O problema epistemológico da complexidade. Mem Martins: Europa-América, 1996.

MORIN, E. Les défis de la complexité: relier les connaissances. Paris: Seuil, 1999.

RICHARDSON, V.; PLACIER, P. Teacher change. In: RichARDSON, V. (Ed.). Handbook of research on teaching. 4. ed. Washington, DC: American Educational Research Association, 2001. p. 905-947.

SILVA, M.I.L. De l'éducation des enfants à la formation des adultes: vers une méthodologie de la recherche-action. 1993. Tese (Doutorado) - Université de Caen, Caen. (não publicado)

SILVA, M.I.L. Práticas educativas e construção de saberes. Lisboa: IIE, 1996.

VEIGA SIMÃO, A.M. A aprendizagem estratégica: construção e avaliação de uma intervenção em estratégias de aprendizagem integrada no currículo escolar. 2000. Tese (Doutorado em Desenvolvimento Curricular e Avaliação da Educação) - Faculdade de Psicologia e de Ciências da Educação, Universidade de Lisboa, Lisboa. (policopiado)

VEIGA SIMÃO, A.M. A aprendizagem estratégica: uma aposta na auto-regulação, n. 2 desenvolvimento curricular. Lisboa: Ministério da Educação, 2002a. 
VEIGA SIMÃO, A.M. Training teachers for learning strategies: developing reflective practices; paper presented at the European Conference on Educational Research, University of Lisbon, 11-14 September 2002b. Disponível em: <http://www.leeds.ac.uk/educol/ documents/00002424.htm>

VEIGA SIMÃO, A.M. Teaching, training and learning strategies in today's school: developing reflective practices. Teacher Education and The Achievement Agenda: problems and promises in policy and practice, ICET 2002 International Yearbook on Teacher Education. Wheeling: Teacher Education and The Achievement Agenda, 2002c.

VEIGA SIMÃO, A.M. A aprendizagem estratégica: intervenção em contexto educativo. Revista Portuguesa de Psicologia, n. 36, p. 139-153, $2002 d$.

WATZLAWICK, P.; WEAKLAND, J.; FISCH, R. Changements, paradoxes et psychothérapie. Paris: Seuil, 1975.

WATZLAWICK, P. The language of change. New York: Basic Books, 1978. 